13

\title{
Токоперехватывающие сетки из анизотропного пиролитического графита в электронных пушках с металлопористым катодом
}

\author{
() С.Д. Журавлев, В.И. Шестеркин \\ АО Научно-производственное предприятие „Алмаз“, \\ 410033 Саратов, Россия \\ e-mail: zhuravlevsd@almaz-rpe.ru
}

Поступило в Редакцию 8 февраля 2019 г.

В окончательной редакции 8 февраля 2019 г.

Принято к публикации 26 февраля 2019 г.

Приведены результаты экспериментальных исследований применения анизотропного пиролитического графита (АПГ) в качестве сеточных структур в мощных СВЧ приборах с металлопористым катодом. Представлены эмиссионные характеристики молибдена, гафния и АПГ в диодах и электронных пушках в зависимости от мощности электронного потока, рассеиваемой на испытуемых образцах, и температуры катода. Показано, что сеточные структуры из АПГ способны рассеивать мощность электронного потока до 20 раз больше, чем сетки из молибдена, и до 9 раз больше, чем сетки из гафния, без появления паразитной термоэлектронной эмиссии.

Ключевые слова: термоэлектронная эмиссия, маталлопористый катод, управляющие сетки, пиролитический графит.

DOI: $10.21883 / J T F .2019 .09 .48075 .45-19$

\section{Введение}

Сеточные структуры используются для низковольтного управления током электронного пучка в импульсных приборах СВЧ диапазона [1,2]. Главным требованием, предъявляемым к приборам данного класса, является отсутствие ВЧ сигнала в паузе между импульсами, который может быть вызван появлением паразитной термоэлектронной эмиссии с сетки в паузах между импульсами вследствие ее чрезмерного нагрева энергией перехваченного электронного потока [3]. В связи с этим к материалу сеточных структур предъявляются жесткие требования по антиэмиссионным свойствам, особенно при работе прибора в режиме малых скважностей (меньше 10). В настоящее время в качестве материала сеточных структур широко используется гафний, обладающий более высокими антиэмиссионными свойствами по сравнению с молибденом [4]. При сравнительно невысокой работе выхода электронов из гафния $(\sim 3.5 \mathrm{eV})$ главным его достоинством является слабая энергия химической связи с барием, адсорбированным на поверхности сетки. Однако при использовании гафния в качестве материала сеток в мощных СВЧ приборах, работающих в режимах малых скважностей, и тем более в квазинепрерывном режиме, возникают проблемы с потерей сеткой управляющих свойств вследствие чрезмерно высоких токов паразитной термоэлектронной эмиссии. В этой связи выбор материала для сеточных структур остается актуальной задачей для разработчиков мощных СВЧ электровакуумных приборов. Недостатком гафния в качестве материала теневых сеток является его „охрупчивание“ при механическом контакте с поверхностью катода, что ограничивает долго- вечность катодно-сеточного узла. Одним из перспективных материалов для изготовления сеточных структур является углерод в различных его модификациях. Так, например, сеточные структуры из углеродных волокон и пиролитического графита используются в генераторных лампах с катодами из торированного вольфрама $[5,6]$. Литературные данные по использованию анизотропного пиролитического графита в СВЧ приборах с металлопористым импрегнированным катодом в настоящее время отсутствуют.

Цель настоящей работы - экспериментальные исследования термоэмиссионных свойств сеточных структур из анизотропного пиролитического графита в электронных пушках с металлопористым импрегнированным катодом и их сравнение с традиционными сеточными структурами из молибдена и гафния.

\section{Термоэмиссионные характеристики молибдена, гафния и АПГ в вакуумных диодах с металлопористым импрегнированным катодом}

Сравнительные исследования термоэмиссионных свойств молибдена, гафния и АПГ проведены в диодах с металлопористым импрегнированным катодом диаметром $6.35 \mathrm{~mm}$ с плоской эмитирующей поверхностью и анодами из исследуемых материалов в форме дисков толщиной $0.2 \mathrm{~mm}$ и диаметром $12 \mathrm{~mm}$, расположенных на расстоянии $0.15 \mathrm{~mm}$ от эмитирующей поверхности катодов. Исследуемые диоды размещались в вакуумной камере с непрерывной откачкой и испытывались при давлении остаточных газов не хуже $2 \cdot 10^{-7}$ Torr. Измерения 

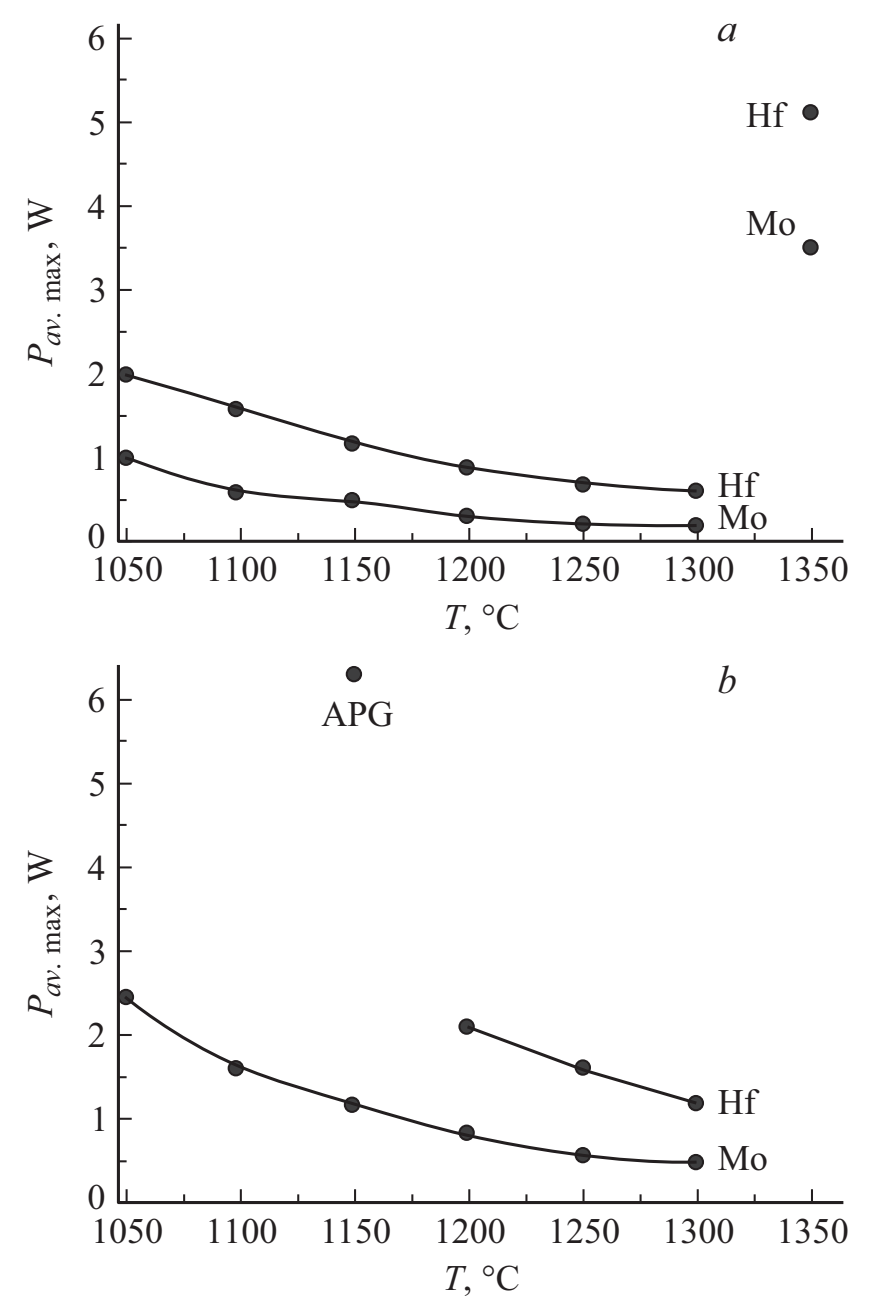

Рис. 1. Зависимости предельной средней мощности электронного потока от температуры катода: $a-$ непрерывный режим; $b$ - импульсный режим: $\tau=40 \mu \mathrm{s} ; Q=250$.

проводились в импульсном режиме с длительностью импульса $\tau=40 \mu \mathrm{s}$ с максимальной скважностью до $Q=250$ и в режиме малых скважностей от $Q=10$ до скважности, близкой к единице, - квазинепрерывный режим. При испытаниях диодов в квазинепрерывном режиме в цепи анода были последовательно включены источник постоянного положительного относительно катода напряжения и модулятор отрицательных импульсов. С катода отбирался импульсный ток с длительностью импульса $(T-\tau)$, равной паузе между импульсами отрицательного напряжения с модулятора в цепи анода, где $T$ - период следования импульсов, $\tau$ - длительность импульса.

Достоверность результатов измерения эмиссионных характеристик материалов обеспечивалась идентичностью конструкций макетов диодов, одинаковой температурой катодов и незначительным отличием вольтамперных характеристик исследуемых диодов, измеренных в непрерывном режиме при температурах катодов $1130^{\circ} \mathrm{C}$.
В процессе измерений регистрировались ток катода и ток термоэлектронной эмиссии с анодов. В импульсном режиме токи регистрировались с помощью осциллографа по падению напряжения на измерительном сопротивлении $R=100 \Omega$. Предельная средняя мощность электронного потока, рассеиваемая на анодах $P_{a v \cdot \max }$ регистрировалась по уровню импульсного тока термоэлектронной эмиссии с анода $\sim 1 \mathrm{~mA}$ и рассчитывалась по формуле $P_{a v \cdot \max }=I_{a} \times U_{a}$, где $I_{a}-$ средний ток анода с учетом скважности, $U_{a}-$ разность потенциалов между катодом и анодом.

Предельные значения средней мощности, рассеиваемые на анодах диодов из молибдена, гафния и АПГ, исследовалась в непрерывном и импульсном режимах при различных температурах катодов (рис. 1).

Для сравнительного анализа термоэмиссионных свойств исследуемых материалов удобнее пользоваться удельной мощностью электронного потока, приводящей к появлению термоэлектронной эмиссии. В непрерывном режиме удельная средняя мощность, рассеиваемая на анодах из молибдена и гафния, при температуре катодов $1050^{\circ} \mathrm{C}$ составляла $\sim 3$ и $\sim 6.6 \mathrm{~W} / \mathrm{cm}^{2}$ соответственно (рис. $1, a$ ). При температуре катода $1140^{\circ} \mathrm{C}$ значения предельной удельной мощности уменьшились до $\sim 1.1$ и $\sim 3.8 \mathrm{~W} / \mathrm{cm}^{2}$. Для данной температуры катода в диоде с анодом из АПГ, даже при средней предельной мощности $\sim 6.3 \mathrm{~W}$ (рис. $1, b$ ), что соответствовало удельной средней мощности $\sim 20 \mathrm{~W} / \mathrm{cm}^{2}$, ток термоэлектронной эмиссии не был зарегистрирован. Дальнейшее увеличение рассеиваемой на аноде из АПГ мощности электронного потока приводило к ухудшению вакуума и снижению эмиссии катода. После восстановления вакуума эмиссия катода полностью восстановилась.

При температуре катода $1350^{\circ} \mathrm{C}$ рассеиваемые на анодах из молибдена и гафния удельные мощности электронного потока $\sim 11$ и $\sim 16.6 \mathrm{~W} / \mathrm{cm}^{2}$ соответственно (рис. $1, a)$ инициировали лавинообразный рост тока катода и тока термоэлектронной эмиссии с анодов. Данный процесс происходил при неизменном значении разности потенциалов в диодах и был вызван возрастающей со временем мощностью обмена энергиями электронных потоков с катода на анод и обратно (ток термоэлектронной эмиссии с анода), который приводил к возрастанию температур катода и анода. Этот неуправляемый процесс развивался скоротечно (в течение нескольких секунд) и завершался ухудшением вакуума и пробоем, если напряжение анода не уменьшалось до безопасного значения. Аналогичные процессы регистрировались в катодно-сеточном узле мощной импульсной ЛБВ и заканчивались разрушением перемычек теневой сетки. 


\section{Термоэмиссионные процессы \\ в электронной пушке \\ с токоперехватывающей сеткой из АПГ и металлопористым импрегнированным катодом}

В электронной пушке был использован катод с плоской эмитирующей поверхностью диаметром $6.35 \mathrm{~mm}$ и планарной сеточной структурой из АПГ толщиной $120 \mu \mathrm{m}$ с квадратными ячейками. Сеточная структура была отделена от поверхности катода вакуумным зазором шириной $150 \mu \mathrm{m}$. При ширине перемычек $80 \mu \mathrm{m}$ и шаге $170 \mu \mathrm{m}$ геометрическая прозрачность сетки составляла 46\%. Отверстия в сеточной структуре были изготовлены методом лазерной абляции [7].

Эмиссионные характеристики сетки из АПГ измерялись при напряжении анода $12 \mathrm{kV}$ относительно катода в режимах с малой скважностью от $Q=10$ до $Q \rightarrow 1$. Защита источника питания в цепи сетки не позволяла увеличивать напряжение на сетке более $160 \mathrm{~V}$. Плотность тока с катода не превышала $1.6 \mathrm{~A} / \mathrm{cm}^{2}$. При увеличении напряжения на управляющей сетке крутизна вольт-амперной характеристики уменьшалась вследствие возрастания тока термоэлектронной эмиссии с сетки, а затем изменяла знак (рис. 2). В точках перегиба вольт-амперных характеристик ток перехвата на сетку и ток термоэлектронной эмиссии с нее были равными по величине.

Значения предельной мощности токоперехвата на сетку, определенные по точкам перегиба кривых, существенно превышали значения, соответствующие появлению термоэлектронной эмиссии с сетки. В точках перегиба кривых величина тока термоэлектронной эмиссии с сетки сопоставима с током перехвата сеткой. Для регистрации начала термоэлектронной эмиссии с управляющей сетки в ее цепи была использована мостиковая схема с разнополярно включенными диодами,

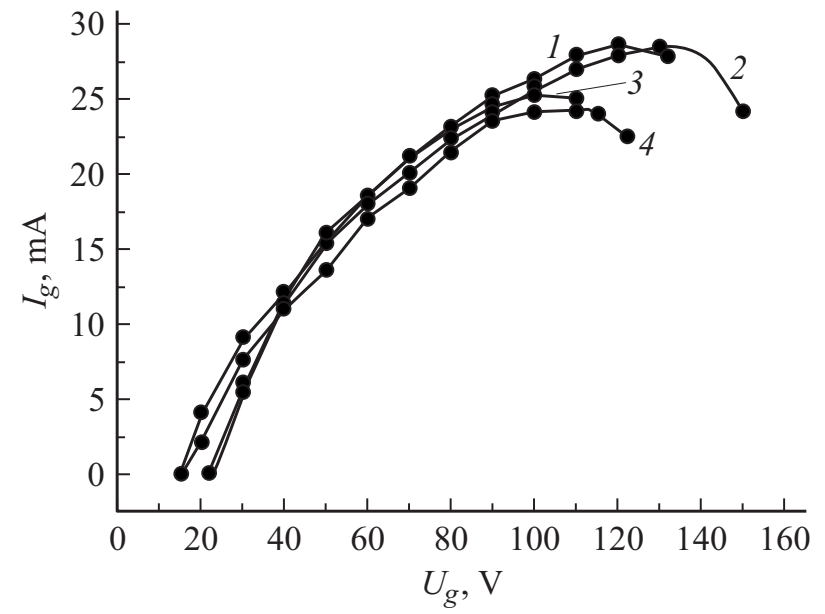

Pис. 2. Зависимости полного среднего тока в цепи сетки от напряжения на сетке при температуре катода $T_{c}=1065^{\circ} \mathrm{C}$ : $1-Q=10 ; 2-Q=6 ; 3-Q=4 ; 4-Q=2.2$.

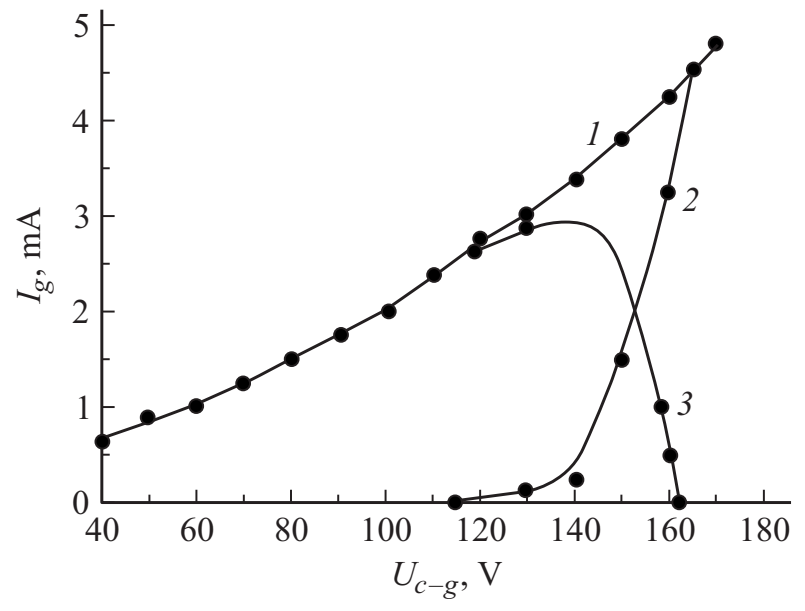

Рис. 3. Зависимости токов в цепи сетки от разности потенциалов катод-сетка $U_{c-g}: 1$ - ток, перехваченный сеткой; $2-$ ток термоэлектронной эмиссии с сетки; 3 - результирующий ток в цепи сетки.

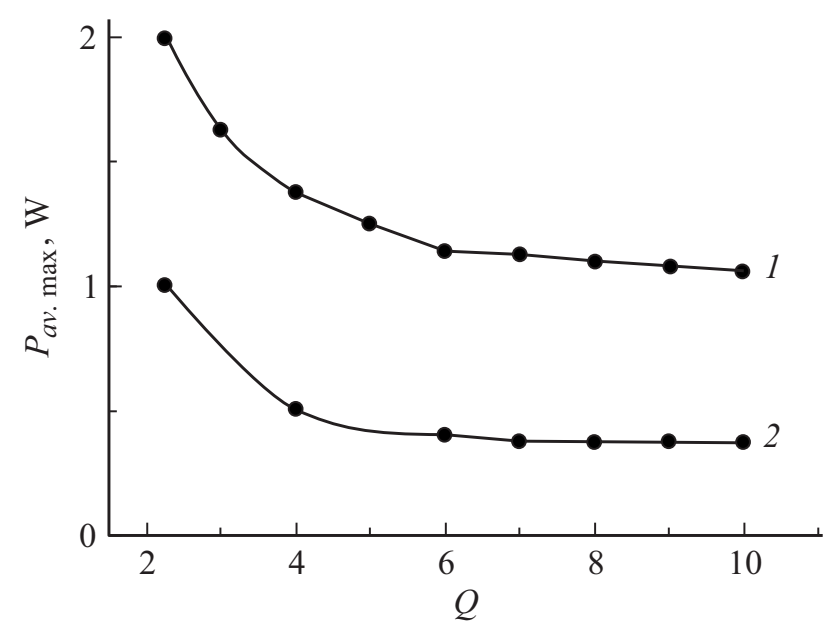

Рис. 4. Зависимость предельной средней мощности перехвата сеткой от скважности: $1-$ по точкам перегиба; $2-$ по току термоэлектронной эмиссии $0.1 \mathrm{~mA}$.

позволяющая разделять протекающие в цепи сетки токи и регистрировать ток, перехваченный сеткой по уровню тока термоэлектронной эмиссии с сетки $0.1 \mathrm{~mA}$ (рис. 3).

В импульсном режиме термоэмиссионный ток с сетки регистрировался в паузе между импульсами с помощью осциллографа на измерительном сопротивлении $R=100 \Omega$ в цепи сетки. Для определения предельной средней мощности токоперехвата на управляющую сетку фиксировалось напряжение на сетке относительно катода, соответствующее термоэмиссионному току сетки $0.1 \mathrm{~mA}$, и ток, перехваченный ею при данном напряжении. Предельная средняя мощность токоперехвата сеткой, соответствующая началу термоэлектронной эмиссии, рассчитанная по точкам перегиба вольтамперных характеристик (рис. 2), существенно превыша- 
ла соответствующие значения, рассчитанные по уровню термоэмиссионного тока с сетки $0.1 \mathrm{~mA}$ (рис. 4).

При скважностях $Q \geq 6$ предельное значение средней мощности практически не изменялось. С увеличением скважности время, соответствующее паузе между соседними импульсами, все больше превосходило время остывания поверхности сетки. При этом ее средняя температура к началу следующего импульса определялась в основном мощностью излучения катода. При значениях скважности $Q \leq 6$ время остывания сетки приближалось к длительности паузы между импульсами и все более превосходило ее при уменьшении скважности [8]. В этом случае средняя температура сетки возрастала с каждым последующим импульсом и для появления термоэлектронной эмиссии требовалось меньшая по величине средняя мощность, рассеиваемая на сетке. В этих режимах мы вправе были ожидать снижения предельной средней мощности, рассеиваемой на сетке, при уменьшении скважности, а не ее возрастание, зарегистрированное экспериментально (рис. 4 при $Q \leq 4)$. Объяснить полученную экспериментальную зависимость можно увеличением эффективной работы выхода поверхности сетки с ростом ее температуры за счет возрастающей десорбции бария. С приближением к непрерывному режиму термоэмиссионный ток определяется исключительно работой выхода непосредственно АПГ, которая составляет $\sim 4.6 \mathrm{eV}$. Предельная мощность токоперехвата при скважности, близкой к единице, сохранялась неизменной.

Данная гипотеза подтвердилась зависимостью тока термоэлектронной эмиссии с сетки из АПГ от средней мощности токоперехвата при различных температурах катода (рис. 5).

При увеличении температуры катода и фиксированной мощности оседания тока на управляющую сетку прирост термоэмиссионного тока замедлялся тем больше, чем

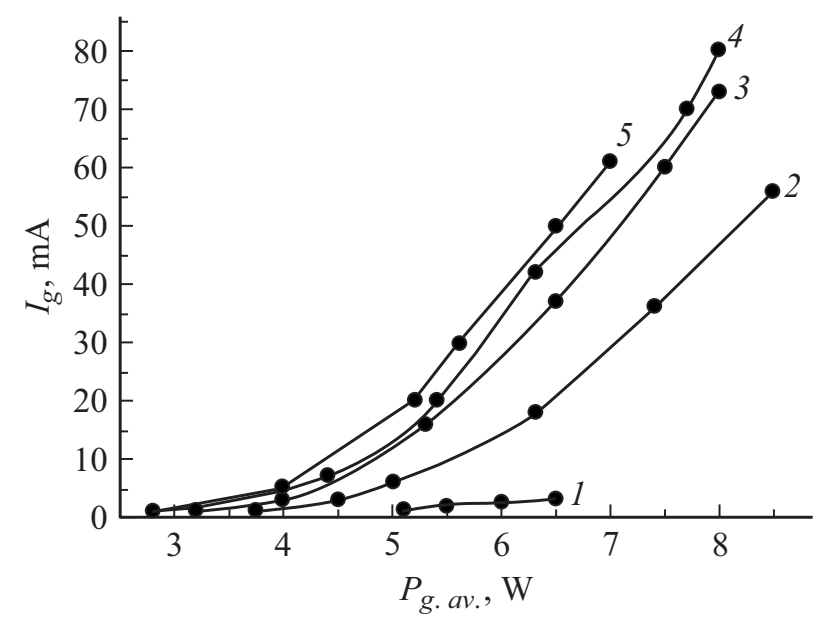

Pис. 5. Термоэмиссионный ток сетки из АПГ в зависимости от средней мощности токоперехвата при различной температуре катода, $T: 1-1000,2-1050,3-1150,4-1190,5-$ $1240^{\circ} \mathrm{C}$

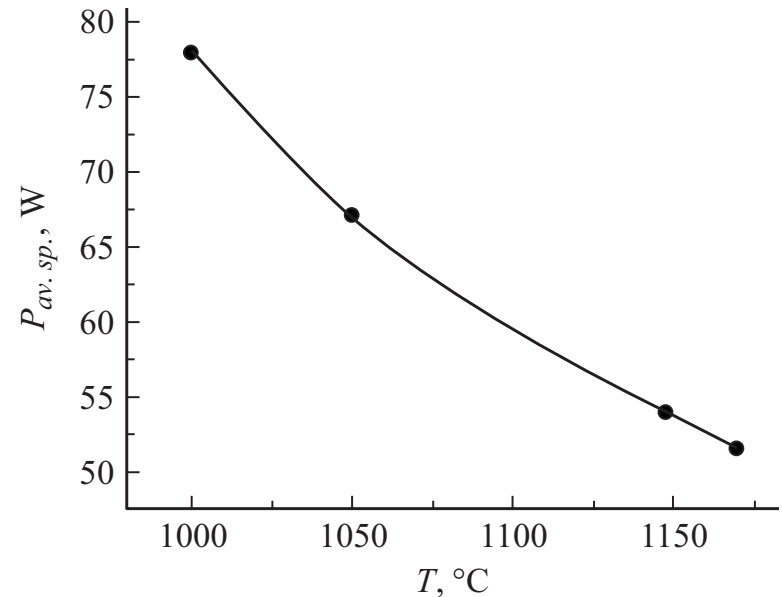

Рис. 6. Зависимость удельной предельно допустимой средней мощности электронного потока на управляющей сетке от температуры катода.

выше температура катода. Величина термоэмиссионного тока определялась температурой сетки и эффективной работой выхода поверхности АПГ, которая возрастала по мере увеличения ее температуры и уменьшением количества адсорбированного на ней бария.

Более удобной величиной, характеризующей предельно допустимую мощность перехвата сеткой, является удельная мощность осаждаемого на сетку электронного потока (рис. 6).

При потенциале управляющей сетки, близком к естественному, электроны осаждались на обращенную к катоду поверхность перемычек сетки. При рабочей температуре металлопористого катода $1050^{\circ} \mathrm{C}$ и плотности отбираемого с катода тока $5 \mathrm{~A} / \mathrm{cm}^{2}$ предельное значение удельной средней мощности для сеток из АПГ составляло $\sim 67 \mathrm{~W} / \mathrm{cm}^{2}$. Это примерно в 22 раза больше, чем для сеток из молибдена, и почти в 9 раз больше, чем для сеток из гафния.

\section{Заключение}

Экспериментально продемонстрированы преимущества использования анизотропного пиролитического графита в качестве материала сеточных структур для управления током электронного пучка в мощных СВЧ электровакуумных приборах, особенно работающих при малых скважностях. Показано, что по своим антиэмиссионным свойствам и теплорассеивающей способности управляющие сетки из АПГ превосходят сетки из молибдена более чем в 20 раз и в примерно 9 раз превосходят сетки из гафния.

\section{Конфликт интересов}

Авторы заявляют, что у них нет конфликта интересов. 


\section{Список литературы}

[1] Григорьев Ю.А., Правдин Б.С., Шестеркин В.И. // Обзоры по электронной технике. Сер. 1. Электроника СВЧ. М.: Издво ЦНИИ Электроника, 1987. Вып. 7. 71 с.

[2] Лысова И.К., Корешкова О.Н. // Обзоры по электронной технике. Сер. 1. Электроника СВЧ. М.: ЦНИИ Электроника, 1976. Вып. 16. № 426. 27 с.

[3] Шестеркин В.И. // Вопросы проектирования и технологии электровакуумных СВЧ приборов. 1981. Вып. 1. № 164. C. $28-29$.

[4] Бабанов А.Ж., Козлов В.И., Авдеев В.Е., Андреев А.А. // Электронная техника. Сер. Материалы. 1980. Вып. 8. С. 14 17.

[5] Брусиловский Г.Л. // Электронная техника. Сер.-4. Электровакуумные и газоразрядные приборы. 1988. Вып. 2. № 121. C. 3-6.

[6] Вильдгрубе В.Г., Цертизский Б.Д., Шаронов В.Н. // Электронная техника. Сер. 4. Газоразрядные приборы. 1989. Вып. 2. № 125. С. 43-52.

[7] Конюшин А.В., Соколова Т.Н., Шалаев П.Д., Шестеркин В.И. // Электронные приборы и устройства СВЧ: Тезисы докладов конференции. 2012. Саратов. С. 70-74.

[8] Максимов В.Ф., Тиктин С.А. // Межвузовский научный сборник. Техническая электроника и электродинамика. 1976. Вып. 1. С. $52-54$ 